\title{
OTRAS OBRAS DE RECIENTE APARICIÓN
}

JOSE MARIA DEANTES-GUANTER, JOSE LOPEZ YEPES, Teoría y práctica de la investigación científica, Madrid, Síntesis, 2002.

Este texto surge del trabajo interdisciplinario de un grupo de investigadores españoles. Luego de varios años de dictar cursos, seminarios y directivas para la construcción de planes de tesis, procesos de investigación y redacción final de informes y otros escritos académico, dichos investigadores han plasmado su experiencia, dudas y reflexiones en forma de manual de guía y consulta. Lo novedoso del presente libro radica en dos perspectivas de abordaje: la aplicación de categorías aristotélicas para avalar el proceso actual de la investigación científica, y la consideración de los estados de ánimos o determinantes subjetivos de los diferentes integrantes de un equipo de búsqueda de conocimiento científico. Además, la idea de comunicación fluida, como condición de posibilidad del buen funcionamiento de un grupo de construcción de conocimiento, es frecuentemente destacada y representa una constante original, entre las consideraciones más previsibles de un texto instrumental como el aquí presentado.

\section{RICARDO MALIANDI, Ética: conceptos y problemas, Buenos Aires, Biblos, 2004.}

Ricardo Maliandi, Doctor en Filosofía por Universidad de Mangucia (Alemania), y reconocido investigador y profesor de Ética en varias instituciones nacionales e internacionales, además de autor de numerosas publicaciones no solamente de ética, sino también de filosofía moderna y contemporánea, ha corregido y aumentado uno de sus libros paradigmáticos, Ética: conceptos y problemas, para su tercera edición. Esta obra se ha convertido en referente obligado para quienes emprenden estudios de ética en nuestro medio. Las inquietudes en torno de los problemas morales se han multiplicado durantes los últimos tiempos; fenómeno que reclama reflexión profesional sobre el tema, así como para identificar las corrientes teóricas más significativas de la historia occidental. Los objetivos del texto se cumplen con creces. Se trata de una nueva superación de sí mismo con la que el Profesor Maliandi, maestro de maestros de ética, nos enriquece teóricamente y nos invita a la reflexión y el debate.

JUAN SAMAJA, Epistemología de la salud, Buenos Aires, Lugar Editorial, 2004.

Uno de los metodológos y epistemólogo más prestigiosos de la Argentina y de la región, el Doctor Juan Samara, ha publicado esta obra en la que asume un desafío, al aportar su elaboración conceptual, de la complejidad de la producción social del conocimiento, al campo de la salud. Emprende (y continúa) una tarea reflexiva sobre la construcción de la racionalidad científica de los enunciados sobre procesos de salud-enfermedad-atención. En este libro se explicitan y aclaran los conceptos indispensables para la constitución de una teoría científica que provea fundamento racional a los principios y criterios que orienten las comprensiones holísticas y complejas de la salud colectiva y del sanitarismo en general. Por otra parte, uno de los aspectos más destacables del texto reside en el esfuerzo realizado por el autor (no únicamente en la presente obra, sino a largo de toda su trayectoria profesional) 
para construir una teoría que no se pliege acríticamente a los cánones de las corrientes positivistas dominantes en las ciencias de la salud. Samaja construye su propia visión de estas problemáticas recuperando la idea de totalidad compleja de lo estudiado. Ello requiere metodología, epistemología y elaboraciones racionales comprometidas con la realidad, más que con formalismos vacíos de contenido o de recetas a priori. Quien estudia seriamente al Profesor Samaja, inicia (o continúa por) un correcto y esclarecido camino por los senderos de la investigación.

NOEMI TESSIO - JORGE DUTRA, Estrategias de la enseñanza de las ciencias naturales, Quilmes, UNQ, 2004.

La publicación aquí presentada es una obra póstuma del Profesor Jorge Dutra, que llega actualmente al público gracias al esfuerzo de la coautora del texto -la Profesora Noemí Tessio-, y a la disposición de la Universidad Nacional de Quilmes. En Estrategias de la enseñanza de las ciencias naturales se despliegan y analizan algunas de las leyes de la naturaleza que rigen nuestra vida. Su comprensión y organización ayudan a llevar una mejor calidad de vida y a relacionarnos con ella con un mayor grado de conciencia. El área de las ciencias naturales ofrece la oportunidad de interactuar con el mundo y posibilita el conocimiento de aspectos relevantes de la realidad. Se abordan, entre otros conocimientos, los correspondientes a la química, la biología y la física. Estas disciplinas constituyen las bases fundamentales para compenetrarnos de la conformación del ambiente en el que habitamos, de sus complejas relaciones, así como de las reglas imperantes en la formación de los distintos elementos que conforman nuestra existencia de seres humanos arrojados al mundo. Un mundo que muestra algunos de sus secretos y accede a brindarnos claves para comprender, aunque más no sea mínimamente, aspectos aproximativos a sus leyes, o a lo que los seres humanos consideramos sus leyes regulativas. El presente texto se ofrece amigable para recorrerlo, didáctico para estudiarlo y abierto a consultas puntuales sobre la enseñanza de las ciencias. 